\title{
Ketamine Inhibits Lung Fluid Clearance through Reducing Alveolar Sodium Transport
}

\author{
Yong Cui, ${ }^{1}$ Hongguang Nie, ${ }^{2}$ Hong Ma, ${ }^{1}$ Lei Chen, ${ }^{3}$ Lin Zhang, ${ }^{4}$ \\ Junke Wang, ${ }^{1}$ and Honglong $\mathrm{Ji}^{5}$ \\ ${ }^{1}$ Department of Anesthesiology, First Affiliated Hospital, China Medical University, Shenyang 110001, China \\ ${ }^{2}$ Institute of Metabolic Disease Research and Drug Development, China Medical University, Shenyang 110001, China \\ ${ }^{3}$ School of Pharmaceutical Sciences, China Medical University, Shenyang 110001, China \\ ${ }^{4}$ Department of Thoracic Surgery, First Affiliated Hospital, China Medical University, Shenyang 110001, China \\ ${ }^{5}$ Department of Biochemistry, University of Texas Health Science Center at Tyler, Tyler, TX 75708, USA
}

Correspondence should be addressed to Yong Cui, cynhg@sina.com

Received 28 May 2011; Revised 13 July 2011; Accepted 1 August 2011

Academic Editor: Daniel T. Monaghan

Copyright ( $) 2011$ Yong Cui et al. This is an open access article distributed under the Creative Commons Attribution License, which permits unrestricted use, distribution, and reproduction in any medium, provided the original work is properly cited.

\begin{abstract}
Ketamine is a broadly used anaesthetic for analgosedation. Accumulating clinical evidence shows that ketamine causes pulmonary edema with unknown mechanisms. We measured the effects of ketamine on alveolar fluid clearance in human lung lobes ex vivo. Our results showed that intratracheal instillation of ketamine markedly decreased the reabsorption of $5 \%$ bovine serum albumin instillate. In the presence of amiloride (a specific ENaC blocker), fluid resolution was not further decreased, suggesting that ketamine could decrease amiloride-sensitive fraction of AFC associated with ENaC. Moreover, we measured the regulation of amiloride-sensitive currents by ketamine in A549 cells using whole-cell patch clamp mode. Our results suggested that ketamine decreased amiloride-sensitive $\mathrm{Na}^{+}$currents (ENaC activity) in a dose-dependent fashion. These data demonstrate that reduction in lung $\mathrm{ENaC}$ activity and lung fluid clearance following administration of ketamine may be the crucial step of the pathogenesis of resultant pulmonary edema.
\end{abstract}

\section{Introduction}

Ketamine is a broadly used anaesthetic for analgosedation, especially during sepsis and cardiovascular instability. Intraoperative pulmonary edema has been reported worldwide following intramuscular or intravenous ketamine administration [1-5]. Pulmonary edema is the abnormal fluid accumulation in the interstitial or alveolar spaces of the lung. Active $\mathrm{Na}^{+}$reabsorption across lung epithelia requires the sequential coordination of the entry of $\mathrm{Na}^{+}$ions through $\mathrm{Na}^{+}$-selective, amiloride-sensitive epithelial $\mathrm{Na}^{+}$channels $(\mathrm{ENaC})$ located at the apical membranes, followed by the extrusion across the basolateral membranes by the energyconsuming $\mathrm{Na}^{+}-\mathrm{K}^{+}$-ATPase. The entry of $\mathrm{Na}^{+}$ions through apical membranes is thought to be the critical step in this process [6-9].

Traditional teaching is that pulmonary edema occurring in patients tends to be cardiac in aetiology, usually with left heart dysfunction which caused back pressure across the pulmonary system, and led to extravasation of fluid into the alveolar space. In patients undergoing anaesthesia, higher afterload as in neurogenic causes or other noncardiogenic pulmonary edema are also encountered [1-3]. Ketamine can clinically induce lung edema as well as increase pulmonary vascular permeability and arterial pressure. However, the effects of ketamine on alveolar $\mathrm{Na}^{+}$transport in human lungs are not known. Alveolar fluid clearance (AFC) has been widely used in understanding lung fluid balance, not only under normal but also pathologic conditions, for example, in acute lung injury (ALI) and acute respiratory distress syndrome (ARDS). Stimulation of AFC accelerates the resolution of pulmonary edema, which benefits gas exchange across the alveolar epithelium [10]. In contrast, impairment of AFC is often related with worsened survival in ALI and ARDS patients $[11,12]$, which leads to the development of pulmonary edema [13]. In this paper, we 
evaluated whether AFC of fluid-instilled human lung lobes is impaired when ketamine is administered into the alveolar space ex vivo, aiming to find the role of ketamine in lung epithelial fluid transport.

As we know, lung alveolar tissue from human is not readily available, and the use of isolated alveolar cells from other species has inherent disadvantages due to species variation. Other problems with acutely isolating cells are possible contamination by microorganisms and damage to the channel proteins by the digestive processes that is necessary for dissociation. A549 cell line is originated from a human alveolar cell carcinoma and possesses many characteristics of Type II alveolar cells [14], which can synthesize phospholipids, consistent with the well-described function of Type II alveolar cells-synthesis of pulmonary surfactant $[15,16]$. Here, we used whole-cell patch clamp technique to identify the effects of ketamine on vectorial $\mathrm{Na}^{+}$ transport in A549 cells in vitro. Our results demonstrate that ketamine can inhibit $\mathrm{ENaC}$ and decrease $\mathrm{ENaC}$-associated fluid clearance across the distal lung epithelium.

\section{Methods and Materials}

2.1. Ex Vivo Human Lung Study. Human lungs were obtained from patients who underwent pneumonectomy for lung cancer (Department of Thoracic surgery, First Affiliated Hospital of China Medical University, Shenyang, China). This study was approved by the responsible ethics committee and by written informed patient consent. There were no pulmonary fibrosis or emphysema as assessed by preoperative computed tomograms. The lung samples excised from patients exposed to stimulants were excluded for our study. Preoperative pulmonary function tests were normal in all patients (see Table 1). The surgical procedure and lung segment chosen were done as described previously $[17,18]$. Briefly, immediately after removal of the lung, we occluded the segmental bronchus with a 10-Fr. balloon catheter and then chose a segment furthest away from the tumor. A warmed normal saline solution $\left(20 \mathrm{~mL}, 37^{\circ} \mathrm{C}\right)$ containing $5 \%$ bovine serum albumin with or without amiloride $(1 \mathrm{mM})$ or ketamine (racemate, $100 \mu \mathrm{M}$ ) was instilled into the distal air spaces through the catheter. We understand that iv perfusion of ketamine will mimic the clinical circumstance. Unfortunately, ketamine cannot be applied via blood vessels of excised human lung lobes due to incompleted pulmonary circulation. Instead, the advantage of intratracheal delivery is that we are able to examine the direct effects of ketamine on alveolar epithelial function. After instillation, the lung segments were inflated with $100 \%$ oxygen at an airway pressure of $7 \mathrm{~cm} \mathrm{H}_{2} \mathrm{O}$. The temperature in this experiment was kept $37^{\circ} \mathrm{C}$ controlled by a waterbath. Alveolar fluid was aspirated $60 \mathrm{~min}$ later and then was centrifuged at $6500 \mathrm{rpm}$ for $10 \mathrm{~min}$, and the supernatant was used for measuring protein concentrations.

2.2. Measurement of Alveolar Fluid Clearance. In the human lung study, the protein concentrations in aspirated solutions were measured by Bradford Method. We estimated AFC by the changes of concentration for bovine serum albumin as water was absorbed. AFC was calculated by the following equation: $\mathrm{AFC}=[(V \mathrm{i}-V \mathrm{f}) / V \mathrm{i}] \times 100$, where $V$ is the volume of the instilled bovine serum albumin solution (i) and the final alveolar fluid (f). $V \mathrm{f}=V \mathrm{i} \times P \mathrm{i} / P \mathrm{f}$, where $P$ represents the protein concentration in the instilled bovine serum albumin solution (i) and the final alveolar fluid (f).

2.3. Cell Culture. A549 cells were obtained from the American Type Culture Collection (ATCC) and grown in RPMI medium (ATCC) supplemented with 10\% fetal bovine serum, penicillin (100 units $/ \mathrm{mL}$ ), and streptomycin $(100 \mu \mathrm{g} / \mathrm{mL})$. Cells were seeded in $75 \mathrm{~cm}^{2}$ flasks and incubated in a humidified atmosphere of $5 \% \mathrm{CO}_{2}, 95 \% \mathrm{O}_{2}$ at $37^{\circ} \mathrm{C}$. For patch clamp studies, cells were lifted by $0.25 \%$ trypsin and $0.53 \mathrm{mM}$ EDTA (Sigma), then seeded at a density of $1 \times 10^{6}$ cells $/ \mathrm{mL}$ on round coverslips ( $8 \mathrm{~mm}$, WPI) situated in 24-well culture plates. Cells were grown in the above medium supplemented with $200 \mathrm{nM}$ dexamethasone to facilitate sodium channel differentiation, the medium was replaced every other day.

2.4. Patch Clamp Recordings. Immediately before each experiment, a coverslip bearing A549 cells was removed from the culture dish and put into a recording chamber, which was mounted on the stage of an inverted fluorescent microscope (Leica DM IRB). For whole-cell mode of patch clamp recording, cells were perfused continuously with extracellular fluid containing (in $\mathrm{mM}$ ): $140 \mathrm{NaCl}, 1.8 \mathrm{CaCl}_{2}, 1 \mathrm{MgCl}_{2}$, and 10 HEPES ( $\mathrm{pH}$ 7.2) [19], following being exposed to ketamine (30 to $1,000 \mu \mathrm{M}$ ) and the $\mathrm{Na}^{+}$channel blocker amiloride $(10 \mu \mathrm{M})$, transepithelial transport indicated by amiloridesensitive currents were measured. Pipettes were made from capillary glass electrode with a P-97 micropipette puller (Sutter). They were back-filled with internal solution (in $\mathrm{mM}$ ): $100 \mathrm{~K}$-gluconate, $40 \mathrm{KCl}, 2 \mathrm{MgCl}_{2}, 0.5 \mathrm{CaCl}_{2}, 2$ $\mathrm{K}_{2}$ ATP, 4 EGTA, and 10 HEPES (pH 7.2) [20]. The pipette resistance varied from 5 to $10 \mathrm{M} \Omega$ when filled with this intracellular fluid. Offset potential was corrected before a gigaohm seal formation. Series resistance and capacitance transients were then compensated with an Axopatch 700B amplifier (Molecular Devices). Currents were digitized with a Digidata 1440A converter (Molecular Devices), filtered through an internal four-pole Bessel filter at $1 \mathrm{kHz}$, and sampled at $2 \mathrm{kHz}$. Inward and outward whole-cell currents were elicited by employing a step-pulse protocol from $-120 \mathrm{mV}$ to $+80 \mathrm{mV}$ in $20 \mathrm{mV}$ increments every $10 \mathrm{~s}$ for $500 \mathrm{~ms}$ duration at a holding potential of $-40 \mathrm{mV}$. Steadystate currents were averaged between 100 and $200 \mathrm{~ms}$ and only the cells with stable baseline currents were included in the results.

2.5. Statistics. Electrophysiological data from patch clamp studies were primarily analyzed with the Clampfit 10.0 (Molecular Devices) software. Furthermore, the measurements were imported into OriginPro 8.0 software (OriginLab) for statistically computation and graphic plotting. Amiloride-sensitive currents (AS) are defined as the difference between total current and amiloride-resistant current. The $\mathrm{IC}_{50}$ values of ketamine inhibition were calculated 
by fitting the dose-response curve with the Hill equation. The whole-cell currents among each single A549 cell were divergent due to various cell size (capacitance), passage, and culture reagents. Thus the whole-cell channel activity was presented as amiloride-sensitive whole-cell current density (ASI density $_{1} \mathrm{pA} / \mathrm{pF}$ ) or normalized currents to the one at $-100 \mathrm{mV}$ of control group.

For analyses of ex vivo alveolar fluid clearance, the mean and SE values of amiloride-sensitive AFC fractions were computed as previously reported [21].

All results are presented as mean \pm SEM. One-way ANOVA computations were used to analyze the difference of the means for normally distributed data. Mann-Whitney test was applied for nonparametric data. $P<0.05$ was considered as significant.

\section{Results}

3.1. Ketamine Reduces AFC in Human Lungs Ex Vivo. To examine the potential effects of ketamine on fluid resolution in distal lung air spaces, we measured AFC in human lung lobes ex vivo under physiological conditions. The clinical data of the patients are summarized in Table 1. Pulmonary function tests were normal in all patients and there were no significant statistic differences among the four groups.

As shown in Figure 1(a), the normal AFC for 5\% bovine serum albumin control group was $14.4 \pm 1.9 \%(n=6)$. These result consisted with previous observations as well as our recent publication in normal human lungs [22, 23]. Intratracheal instillation of ketamine $(100 \mu \mathrm{M})$ markedly decreased the reabsorption of the 5\% BSA instillate (10.2 \pm $3.6 \%, P<0.05$ versus control, $n=5$ ). We asked the question of whether ketamine inhibits $\mathrm{ENaC}$ activity. To address this issue, we applied a specific $\mathrm{ENaC}$ inhibitor, amiloride $(1 \mathrm{mM})$. This compound reduced AFC to $6.6 \pm$ $2.8 \%(P<0.01$ versus control, $n=5)$. Ketamine (keta + amil) did not further reduce fluid resolution significantly $(9.3 \pm 3.7 \%, P>0.05$ versus ketamine group, $n=5)$. Under these experimental conditions, ketamine can only alter AFC fractions contributed by non-ENaC pathways. These data suggest that ketamine could almost completely decrease amiloride-sensitive fraction of AFC associated with $\mathrm{ENaC}$ (Figure 1(b)). These ex vivo data demonstrated that ketamine might decrease transalveolar fluid clearance contributed by $\mathrm{ENaC}$.

\subsection{Ketamine Decreases Amiloride-Sensitive Whole-Cell} $\mathrm{Na}^{+}$Currents in A549 Cells. Because ketamine decreased amiloride-sensitive fraction of AFC, we postulated that ketamine may directly inhibits $\mathrm{ENaC}$ activity. We carried out whole-cell patch clamp studies in A549 cells (a human alveolar epithelial cell line) to further explore the mechanisms for ketamine-reduced AFC.

Figure 2(a) showed representative recordings of wholecell currents in the absence and presence of ketamine, ranging from 0 to $1,000 \mu \mathrm{M}$ in one A549 cell, $10 \mu \mathrm{M}$ amiloride was then added to compute the amiloride-sensitive currents. Ketamine decreased whole-cell $\mathrm{Na}^{+}$currents at each holding potential in a dose-dependent manner. To compute the $\mathrm{IC}_{50}$ value for ketamine, a dose-response curve was plotted with the amiloride-sensitive currents ( $\mathrm{ENaC}$ activity) measured at cell membrane potential of $-100 \mathrm{mV}$ (Figure 2(b)). The minimum value $(0 \mu \mathrm{M})$ represents the original concentration without drug administration and an $\mathrm{IC}_{50}$ value of $63.5 \pm$ $21.7 \mu \mathrm{M}$ for ketamine was calculated when the data were fitted with the Hill equation. Amiloride-sensitive current density- $\left(\mathrm{ASI}_{\text {density }}{ }^{-}\right)$voltage curves for average control currents (control), in the presence of different concentrations of ketamine $(30 \mu \mathrm{M}$ to $1 \mathrm{mM})$ were shown in Figure 2(c). $100 \sim 1000 \mu \mathrm{M}$ ketamine could inhibit the amiloride-sensitive $\mathrm{Na}^{+}$currents significantly in patch-clamped A549 cells at each commanding potential $(P<0.05$ versus control, $n=$ 7). In contrast, even the maximum dosage of DMSO used for dissolving amiloride had no obvious effect (data not shown).

\section{Discussion}

In this paper, we studied the effects of ketamine on human alveolar epithelial fluid clearance which has important clinical significance. First, several case reports have shown that ketamine is a possible reason for lung edema in patients during intraoperative period $[1-3,5]$. If this effect occurred at the level of the alveolar or distal airway epithelium, then the threshold for developing alveolar edema could be downregulated or the resolution of edema, in which active ion transport plays an important role, might be reduced by ketamine [8]. In addition, ketamine is widely used for analgosedation in patients with cardiac and hemodynamic instability who are liable to the occurrence of lung edema. In these patients, the decreased of AFC is associated with increased mortality [12]. Much effort has therefore been focused on identifying the pathogenic mechanisms underlying disturbed AFC in patients and how AFC can be maintained.

4.1. Ketamine Inhibits Fluid Resolution in Human Lungs. To investigate whether ketamine inhibited alveolar $\mathrm{Na}^{+}$ transport in the human lung, AFC was measured by a way of fluid instillation. In this setup, the rate of ex vivo AFC was significantly reduced in human lobes intratracheally administrated ketamine. Addition of amiloride to the instillate decreased AFC by about $50 \%$, which is in accordance with previous studies $[17,18,22,24]$. Previous studies showed that S-ketamine via iv at clinically relevant bolus concentrations does not affect AFC in rats [25], the difference might result from the many divergent properties of ENaC between different species. For example, cpt-cGMP activates human but not murine ENaC activity [22]. The responses to cpt-cAMP are different between human and murine $\mathrm{ENaC}$, too [26]. It is conceivable that ketamine may reduce $\mathrm{ENaC}$ activity in human lungs but may not alter rat counterpart.

Then whether ketamine acts directly on transepithelial sodium transport? It is well known that alveolar fluid clearance is majorly determined by amiloride-sensitive sodium transport pathway $[27,28]$. During this study, we applied $\mathrm{ENaC}$-specific inhibitor to identify the contribution of 
TABLE 1: Clinical characteristics of patients.

\begin{tabular}{lcccc}
\hline & Control $(n=6)$ & Amiloride $(n=5)$ & Ketamine $(n=5)$ & Keta+am $(n=5)$ \\
\hline Age (year) & $60.0 \pm 8.6$ & $64.8 \pm 11.4$ & $60.0 \pm 8.1$ & $50.4 \pm 3.9$ \\
Male (\%) & 50 & 40 & 60 & 80 \\
$\mathrm{PaO}_{2}(\mathrm{mmHg})$ & $87.4 \pm 4.5$ & $86.9 \pm 6.8$ & $83.7 \pm 8.3$ & $90.2 \pm 6.0$ \\
$\mathrm{VC}(\mathrm{L})$ & $3.3 \pm 0.5$ & $3.1 \pm 0.9$ & $3.2 \pm 0.9$ & $4.2 \pm 0.7$ \\
FEV1.0 actual value (L) & $2.4 \pm 0.4$ & $2.4 \pm 0.9$ & $9.7 \pm 0.8$ & $3.2 \pm 0.5$ \\
FEV $_{1.0}$ actual/predicted (\%) & $96.3 \pm 21.6$ & $3.1 \pm 0.2 \pm 10.7$ & $3.2 \pm 0.9$ & $97.3 \pm 10.4$ \\
FVC actual value (L) & $3.2 \pm 0.4$ & $113.0 \pm 24.1$ & $92.5 \pm 9.6$ & $3.8 \pm 0.6$ \\
FVC actual/predicted (\%) & $103.6 \pm 27.8$ & $77.9 \pm 7.9$ & $84.0 \pm 10.0$ & $87.5 \pm 4.8$ \\
FEV & $74.6 \pm$ FVC (\%) & $74.6 \pm 10.3$ & $83.9 \pm 3.8$ \\
\hline
\end{tabular}

VC: vital capacity; $\mathrm{FEV}_{1.0}$ : forced expiratory volume in $1.0 \mathrm{~s}$; FVC: forced vital capacity. One-way ANOVA.

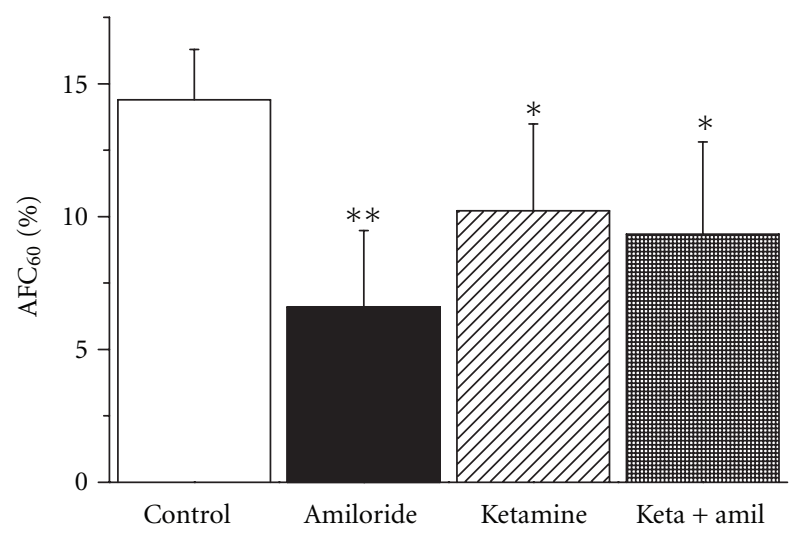

(a)

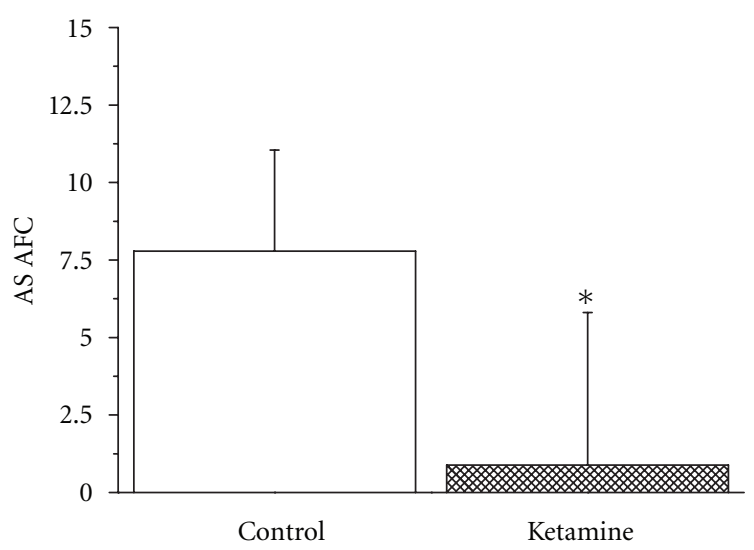

(b)

Figure 1: Effects of ketamine on alveolar fluid clearance in isolated human lungs. (a) Lungs were treated with 5\% bovine serum albumin dissolved in physiologic saline solution in the absence of drugs (control), in the presence of amiloride ( $1 \mathrm{mM}), \mathrm{ketamine}(100 \mu \mathrm{M})$, and both $(\mathrm{Keta}+\mathrm{Amil}) . \% \mathrm{AFC}_{60}$ represents the AFC percentage after $60 \mathrm{~min}$. (b) Amiloride-sensitive (AS) AFC. Average AFC values are presented as the mean \pm SEM, one-way ANOVA. ${ }^{*} P<0.05,{ }^{*} P<0.01 . n=5-6$.

$\mathrm{ENaC}$ to the total AFC. Our results showed that ketamine decreased amiloride-sensitive fraction of AFC, which reflects $\mathrm{ENaC}$ activity. Ketamine may regulate potassium channels, cystic fibrosis transmembrane conductance regulator, $\mathrm{Na}^{+}-$ $\mathrm{K}^{+}$-ATPase, and other transport pathways that coordinately regulate alveolar fluid balance with $\mathrm{ENaC}$ and contribute to alveolar fluid absorption. However, the evidence is not available to date. The effects of ketamine on the other channels mentioned above still await for future studies.

When ketamine was instilled into the lung segments together with amiloride, no further inhibition effect occurred. Because the effect of this combination showed no statistic difference from the effect of each drug alone, these findings demonstrate that ketamine indeed inhibited the amiloride-sensitive component of AFC, suggesting that ketamine and amiloride may both act through the same mechanism, blockade of ENaC competitively. On the other hand, ketamine may also inhibit accessory $\mathrm{Na}^{+}$transport sites that were necessary for the inhibition of amiloride, which could explain the reason why amiloride did not induce an additional decrease of alveolar fluid clearance after administration of ketamine. Ketamine might impair the airspace fluid balance by disturbing both alveolar fluid resolution and turnover in human lungs.

\subsection{Ketamine Inhibits Alveolar Ion Transport in A549 Cells.} Ketamine inhibited alveolar sodium transport in rat pneumocytes [25]. ENaC has been documented in type I and II alveolar cells both physiologically and biochemically. Our ex vivo data imply that ketamine may eliminate $\mathrm{ENaC}$ activity. To corroborate these observations, we measured $\mathrm{ENaC}$ activity in A549 cells (a human type II alveolar cell line). We found that $\mathrm{ENaC}$ activity was significantly decreased by ketamine in a dose-dependent manner. Our patch clamp data in A549 cells are in good agreement with the ex vivo AFC results. The plasma concentration of ketamine after administration of $2 \mathrm{mg} / \mathrm{kg}$ intravenously has been reported to be $1.1 \times 10^{-4} \mathrm{M}$ [29]. In our study, the same concentration markedly decreased alveolar AFC in human lungs and amiloride-sensitive currents in A549 cells. Because ketamine is cell permeable, the concentration in alveolar fluid may be close to that in plasma during continuously 


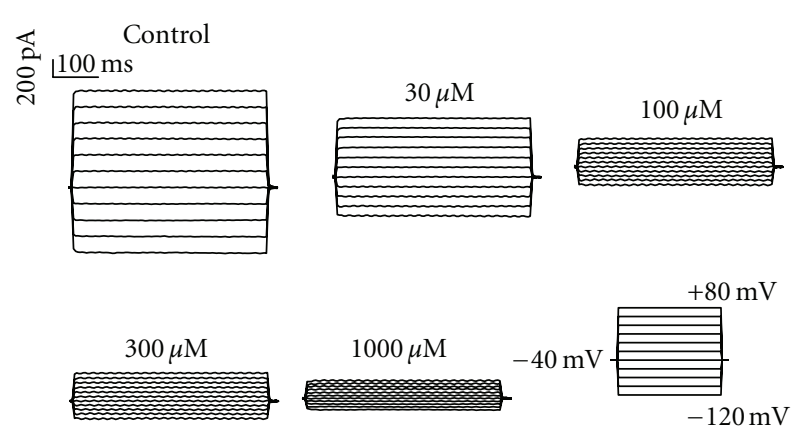

(a)

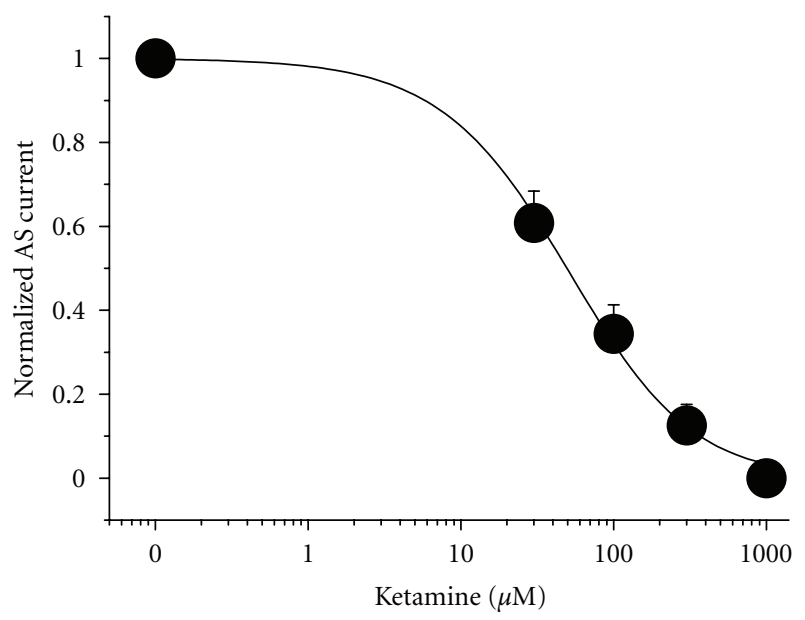

(b)

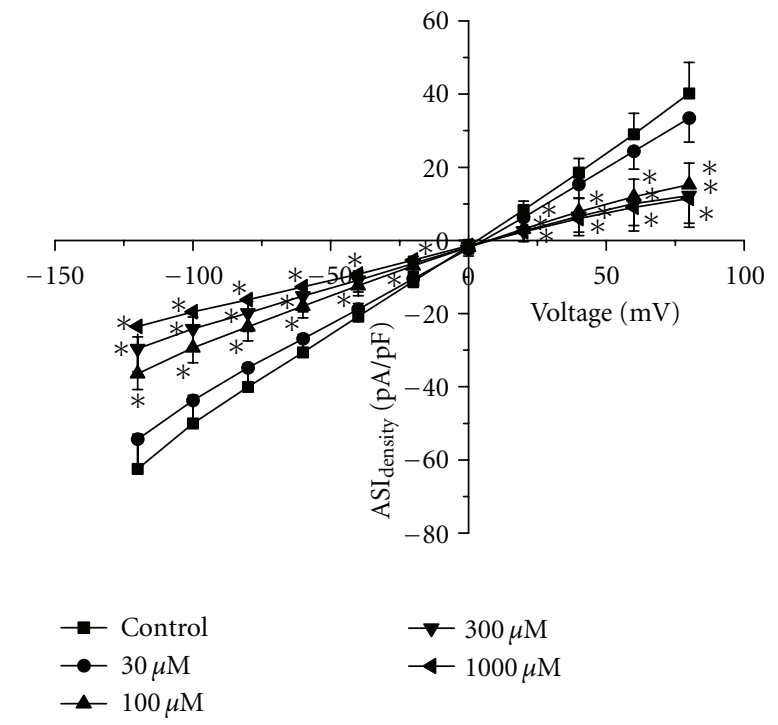

(c)

FIGURE 2: Patch clamp recordings of amiloride-sensitive currents in A549 cells. (a) Representative recordings of amiloride-sensitive current traces in a cell before (control) and after delivery of different concentrations of ketamine ( $30 \mu \mathrm{M}$ to $1 \mathrm{mM})$ to the bath. (b) Concentrationdependent inhibition of whole-cell currents by ketamine. For each cell, inward currents recorded at $-100 \mathrm{mV}$ were measured during perfusion with external solutions. Amiloride-sensitive (AS) currents were normalized to the current at $-100 \mathrm{mV}$ of control. IC 50 was calculated by best fitting the raw data points to the Hill equation. Inorm $=1 /\left(1+\left(\text { ketamine } / \mathrm{IC}_{50}\right)\right)^{\text {coe }}$. (c) Amiloride-sensitive current density- $\left(\mathrm{ASI}_{\text {density }}{ }^{-}\right)$voltage curves for average control currents (control), in the presence of different concentrations of ketamine $(30 \mu \mathrm{M}$ to $1 \mathrm{mM})$. Average values are presented as the mean \pm SEM. One-way ANOVA. ${ }^{*} P<0.05, n=7$.

intravenous infusion. In addition, ketamine-induced lung injury may facilitate the leaking of this anesthesiologic reagent into edematous airspaces. These inhibitory effects of ketamine on $\mathrm{ENaC}$ thus are implicated in clinically reported lung edema $[1-3,5]$. In addition to the direct inhibitory effects on $\mathrm{ENaC}$, ketamine may cause pulmonary edema by stimulating nervous system $[1,3]$ and increasing pulmonary artery pressure [30].

\section{Conclusion}

To conclude, our study demonstrated that ketamine can inhibit $\mathrm{ENaC}$ and decrease $\mathrm{ENaC}$-associated fluid clearance across the distal lung epithelium, which may be the crucial step of the pathogenesis of ketamine-induced pulmonary edema.

\section{Acknowledgments}

This paper is supported by the National Natural Science Foundation of China (30971181) to H. Nie and NIH HL87017 to H. Ji.

\section{References}

[1] C. K. Pandey, N. Mathur, N. Singh, and H. C. Chandola, "Fulminant pulmonary edema after intramuscular ketamine," 
Canadian Journal of Anesthesia, vol. 47, no. 9, pp. 894-896, 2000.

[2] S. Parthasarathy, M. Ravishankar, S. Selvarajan, and T. Anbalagan, "Ketamine and pulmonary oedema-report of two cases," Indian Journal of Anaesthesia, vol. 53, no. 4, pp. 486-488, 2009.

[3] J. L. Murphy Jr., "Hypertension and pulmonary oedema associated with ketamine administration in a patient with a history of substance abuse," Canadian Journal of Anaesthesia, vol. 40, no. 2, pp. 160-164, 1993.

[4] J. Boutureira, C. M. Trim, and K. K. Cornell, "Acute pulmonary edema after diazepam-ketamine in a dog," Veterinary Anaesthesia and Analgesia, vol. 34, no. 5, pp. 371-376, 2007.

[5] N. Baduni, M. K. Sanwal, A. Jain, and N. Kachru, "Recurrent episodes of intractable laryngospasm followed by laryngeal and pulmonary oedema during dissociative anaesthesia with intravenous ketamine," Indian Journal of Anaesthesia, vol. 54, no. 4, pp. 364-365, 2010.

[6] S. Matalon and H. O'Brodovich, "Sodium channels in alveolar epithelial cells: molecular characterization, biophysical properties, and physiological significance," Annual Review of Physiology, vol. 61, pp. 627-661, 1999.

[7] W. Song and S. Matalon, "Modulation of alveolar fluid clearance by reactive oxygen-nitrogen intermediates," American Journal of Physiology, vol. 293, no. 4, pp. L855-L858, 2007.

[8] M. A. Matthay, H. G. Folkesson, and C. Clerici, "Lung epithelial fluid transport and the resolution of pulmonary edema," Physiological Reviews, vol. 82, no. 3, pp. 569-600, 2002.

[9] H. G. Nie, L. Chen, D. Y. Han et al., "Regulation of epithelial sodium channels by cGMP/PKGII," Journal of Physiology, vol. 587, no. 11, pp. 2663-2676, 2009.

[10] G. D. Perkins, D. F. McAuley, D. R. Thickett, and F. Gao, “The $\beta$-agonist lung injury trial (BALTI): a randomized placebocontrolled clinical trial," American Journal of Respiratory and Critical Care Medicine, vol. 173, no. 3, pp. 281-287, 2006.

[11] L. B. Ware and M. A. Matthay, "Alveolar fluid clearance is impaired in the majority of patients with acute lung injury and the acute respiratory distress syndrome," American Journal of Respiratory and Critical Care Medicine, vol. 163, no. 6, pp. 1376-1383, 2001.

[12] M. A. Matthay, L. Robriquet, and X. Fang, "Alveolar epithelium: role in lung fluid balance and acute lung injury," Proceedings of the American Thoracic Society, vol. 2, no. 5, pp. 206-213, 2005.

[13] D. L. A. Wyncoll and T. W. Evans, "Acute respiratory distress syndrome," The Lancet, vol. 354, no. 9177, pp. 497-501, 1999.

[14] M. Lieber, B. Smith, A. Szakal, W. Nelson-Rees, and G. Todaro, "A continuous tumor cell line from a human lung carcinoma with properties of type II alveolar epithelial cells," International Journal of Cancer, vol. 17, no. 1, pp. 62-70, 1976.

[15] S. Matalon, "Mechanisms and regulation of ion transport in adult mammalian alveolar type II pneumocytes," American Journal of Physiology, vol. 261, no. 5, pp. C727-C738, 1991.

[16] F. P. G. Ridge, M. Duszyk, and A. S. French, "A large conductance, $\mathrm{Ca}^{2+}$-activated $\mathrm{K}^{+}$channel in a human lung epithelial cell line (A549)," Biochimica et Biophysica Acta, vol. 1327, no. 2, pp. 249-258, 1997.

[17] T. Sakuma, X. Gu, Z. Wang et al., "Stimulation of alveolar epithelial fluid clearance in human lungs by exogenous epinephrine," Critical Care Medicine, vol. 34, no. 3, pp. 676681, 2006.

[18] T. Sakuma, X. Gu, M. Sugita, M. Sagawa, M. Sakuda, and H. Toga, "Catecholamine clearance from alveolar spaces of rat and human lungs," Respiration, vol. 72, no. 2, pp. 189-196, 2005.

[19] N. Voilley, E. Lingueglia, G. Champigny et al., "The lung amiloride-sensitive $\mathrm{Na}^{+}$channel: biophysical properties, pharmacology, ontogenesis, and molecular cloning," Proceedings of the National Academy of Sciences of the United States of America, vol. 91, no. 1, pp. 247-251, 1994.

[20] H. G. Nie, T. Tucker, X. F. Su et al., "Expression and regulation of epithelial $\mathrm{Na}^{+}$channels by nucleotides in pleural mesothelial cells," American Journal of Respiratory Cell and Molecular Biology, vol. 40, no. 5, pp. 543-554, 2009.

[21] D. Y. Han, H. G. Nie, X. Gu et al., " $\mathrm{K}^{+}$channel openers restore verapamil-inhibited lung fluid resolution and transepithelial ion transport," Respiratory Research, vol. 11, article 65, 2010.

[22] D. Y. Han, H. G. Nie, X. F. Su et al., "CPT-cGMP stimulates human alveolar fluid clearance by releasing external $\mathrm{Na}^{+}$selfinhibition of ENaC," American Journal of Respiratory Cell and Molecular Biology. In press.

[23] J. A. Frank, R. Briot, J. W. Lee, A. Ishizaka, T. Uchida, and M. A. Matthay, "Physiological and biochemical markers of alveolar epithelial barrier dysfunction in perfused human lungs," American Journal of Physiology, vol. 293, no. 1, pp. L52L59, 2007.

[24] M. A. Matthay, C. Clerici, and G. Saumon, "Invited review: active fluid clearance from the distal air spaces of the lung," Journal of Applied Physiology, vol. 93, no. 4, pp. 1533-1541, 2002.

[25] M. M. Berger, B. Pitzer, S. Zügel et al., "Alveolar but not intravenous S-ketamine inhibits alveolar sodium transport and lung fluid clearance in rats," Anesthesia and Analgesia, vol. 111, no. 1, pp. 164-170, 2010.

[26] R. Molina, D.-Y. Han, X.-F. Su et al., "Cpt-cAMP activates human epithelial sodium channels via relieving selfinhibition," Biochimica et Biophysica Acta, vol. 1808, no. 7, pp. 1818-1826, 2011.

[27] S. Matalon, D. J. Benos, and R. M. Jackson, "Biophysical and molecular properties of amiloride-inhibitable $\mathrm{Na}^{+}$channels in alveolar epithelial cells," American Journal of Physiology, vol. 271, no. 1, pp. L1-L22, 1996.

[28] M. Laffon, C. Jayr, P. Barbry et al., "Lidocaine induces a reversible decrease in alveolar epithelial fluid clearance in rats," Anesthesiology, vol. 96, no. 2, pp. 392-399, 2002.

[29] E. F. Domino, E. K. Zsigmond, and L. E. Domino, "Plasma levels of ketamine and two of its metabolites in surgical patients using a gas chromatographic mass fragmentographic assay," Anesthesia and Analgesia, vol. 61, no. 2, pp. 87-92, 1982.

[30] G. F. Rich, C. M. Roos, S. M. Anderson, M. O. Daugherty, and D. R. Uncles, "Direct effects of intravenous anesthetics on pulmonary vascular resistance in the isolated rat lung," Anesthesia and Analgesia, vol. 78, no. 5, pp. 961-966, 1994. 

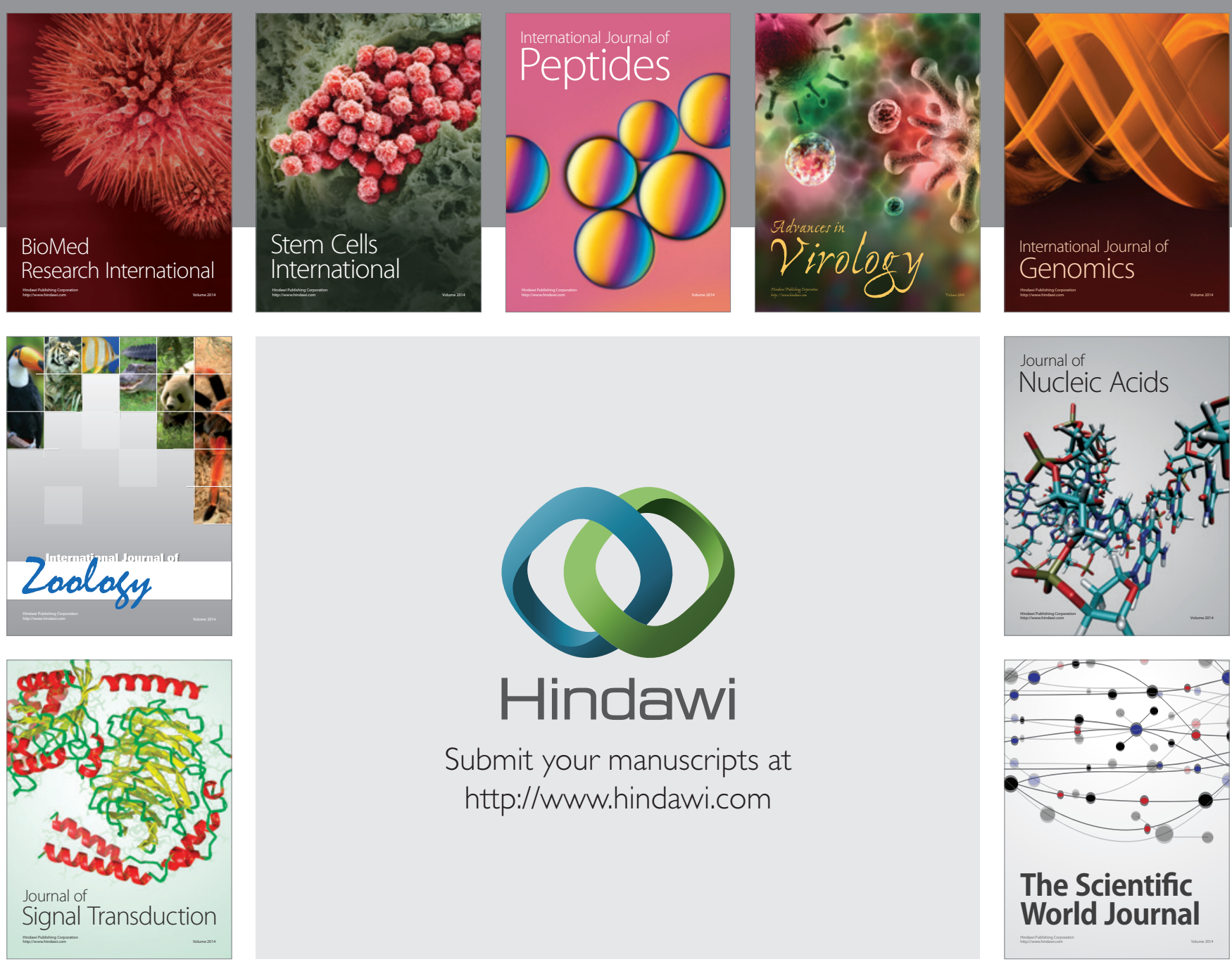

Submit your manuscripts at

http://www.hindawi.com
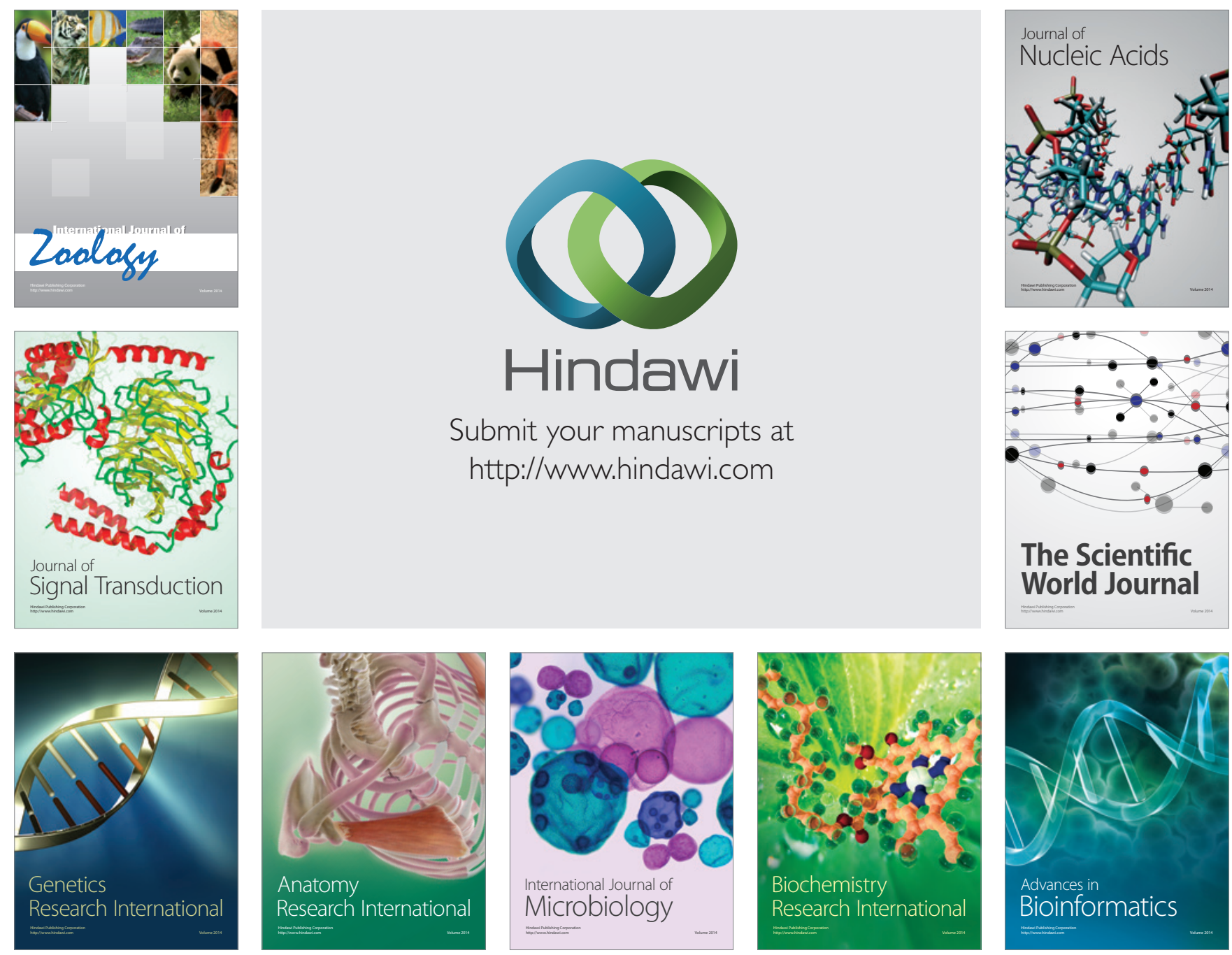

The Scientific World Journal
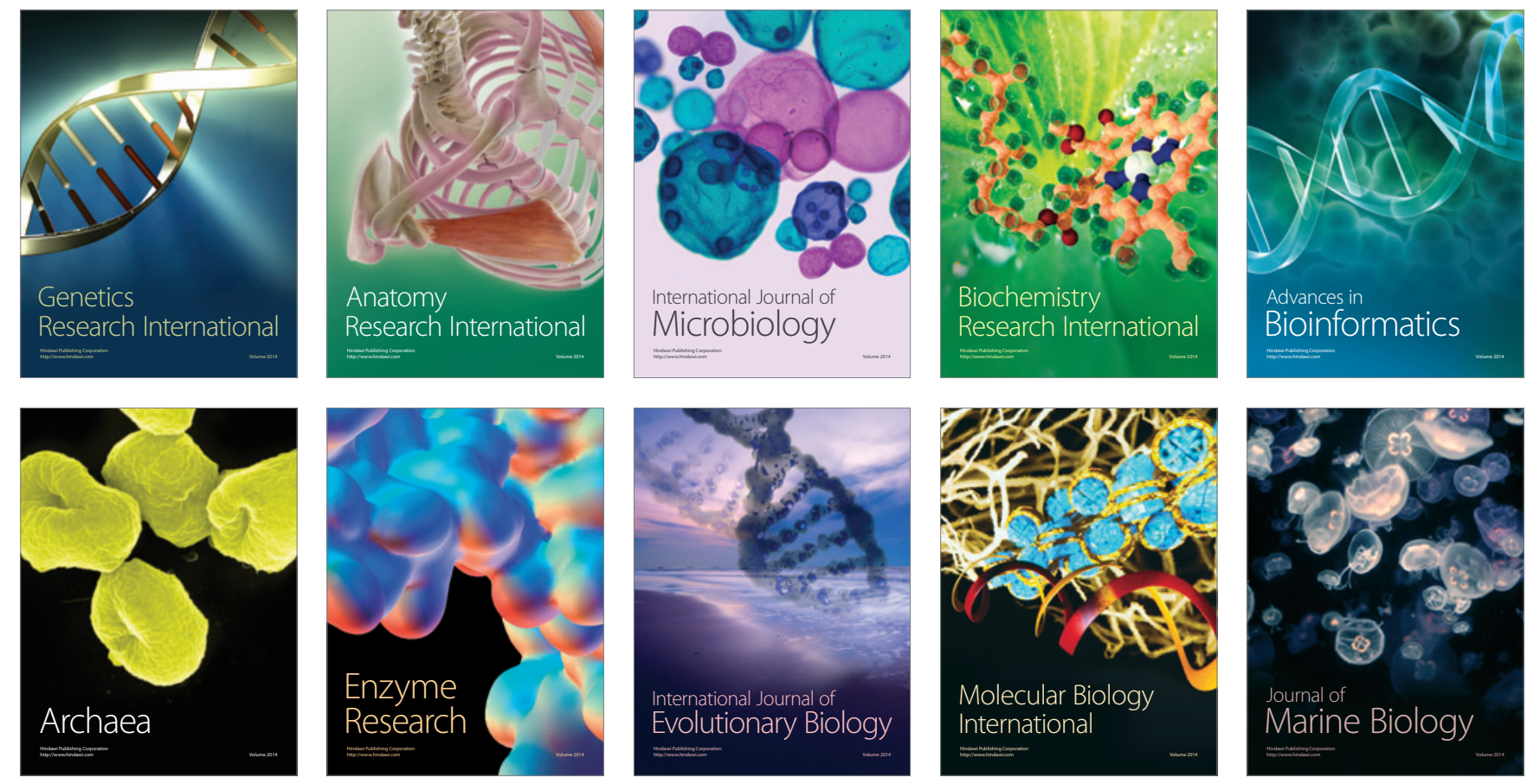